\title{
IDENTIFICATION OF THE STAGE OF PURCHASE BEHAVIOUR RELATED TO FACIAL BIOMETRIC TECHNOLOGY AMONG BUSINESSES IN SLOVAKIA
}

\author{
Michal Budinský ${ }^{1}$, Janka Táborecká-Petrovičová ${ }^{2}$
}

\begin{abstract}
The implementation of new technologies among businesses is a common practice, in order to keep their market position and to enhance their performance. As the world changes further, high-tech innovations and applications take place. Notably, biometric technologies and the scope of their usage is a recently discussed topic as they represent a huge potential for the improvement of business processes in distinctive areas. Their implementation in businesses generates valuable information about customers and allows businesses to more precisely fulfill their needs and requirements. Related to this, questions about business interest and preparedness for these technologies is in place. The main aim of this paper is to identify the stage of purchase behavior of the investigated businesses operating in Slovakia related to facial biometric technology. Specifically, we focused our attention on the identification of businesses in reference to a particular stage of the AIDA model and further devoted to the description of business from individual stages.
\end{abstract}

JEL Classification Numbers: O30, O31, DOI: https://doi.org/10.12955/peb.v1.14

Keywords: Biometric Technologies. Facial Biometrics. AIDA Model. Purchase Behavior.

\section{Introduction}

Biometric technologies and their usage in a market represent an interesting topic for our research. Even though biometrics are not a novelty and their usage is dated from the end of the 19th century, modern ways of their utilization and new functionalities represent a huge potential for businesses interested in this field. Within these technologies it is possible to gather valuable information about customers, in order to better satisfy their more demanding needs with higher effectiveness. In relation to this, we found it interesting to investigate the current situation in a Slovak market about the awareness and readiness of businesses to implement facial biometric technologies.

\section{Literature Review}

In order to enter an examined issue, we would like to focus our attention on the basic description of the AIDA and STDC model. In general, these models describe the degree of customer readiness related to his purchase behavior. Firstly, we are talking about attention, which is also called "awareness" and refers to whether a consumer finds a particular product as attractive. Consequently, when a product has attention among customers, it is very important to keep it, which is sometimes more difficult. In this step, we are talking about the creation of "interest" for a product or service. So, customers know about a particular product and certain level of interest is developed. Next, after attention and interest are developed, "desire" for the product is required to be established. In these terms, desire refers to the product/service evaluation and decision-making process. Finally, the last step is about calling a consumer to "action", thus to purchase a product/technology.

It means that based on stages of the AIDA model among consumers, we can classify them into four groups - those who are aware of the product, those who harbor some level of interest in the product, those who are thinking about the product seriously and evaluate it and finally, those who initiated an intention to purchase the product. These four groups of customers represent an interesting source of information for companies and their marketers, as well as create a picture about the distribution of their potential customers into certain levels of readiness for the company's product. However, a study of Suggett (2017) showed that in relation to the stages of the AIDA model, customers' perception of a new technology market potential is different.

Within the STDC model, the very fist stage "See" refers to a group of potential customers that currently gained basic information about your product/service and create wide audience. The next stage "Think" is represented by those customers that have an interest in your product or consider it for purchase. The following stage of "Do" is connected with customers that definitely decided about purchasing your product/service or those who already made a purchase. The last step of this model, "Care", refers to the customers who made at least 2 purchases of your product and the aim of the business is to care about them with post-purchase services (Hart, 2018).

\footnotetext{
${ }^{1}$ Matej Bel University, Faculty of Economics, Slovakia, michal.budinsky@umb.sk

${ }^{2}$ Matej Bel University, Faculty of Economics, Slovakia, janka.taborecka@umb.sk
} 
In general, we can see an analogy between these two models, especially in the first two phases. According to the AIDA as well as the STDC model, first phase represents the development of attention among potential customers or providing basic information about your products. The second stage of these models is accompanied by showing an interest in a particular product or service by your customers. Consequently, the third and fourth stage of the AIDA model refers to the desire about buying a product and realization of a purchase. However, these two steps are covered in the "Do" phase of the STDC model. Therefore, a difference between these models can be found in case of the "Care" stage, where the STDC model goes beyond the AIDA model and is focused also on customers who already made some purchases. Sometimes, "Care" is replaced by "Coddle" which describe that businesses should take special care of their existing customers. To sum it up, with the help of these models we are able to identify the actual buying process stages of customers.

Actually, we notice that businesses are still often improving their products, services, and processes in order to keep in touch with customers and to stay competitive in a market. Innovations of businesses are spread across all departments to get the best results. While information and communication technologies change the world further, businesses will still utilize more new technologies and features. For this reason, it is not a surprise that every day more references to the utilization of biometrics or biometric technologies are released.

Since the new technology on which we are focused is a new facial biometric technology, we will start with essential definitions. Facial biometrics or face recognition technology belongs to the family of biometrics solutions. This technology is able to identify, to measure and to connect specific characteristics of persons for the purpose of their identification and authentication. This technology is implemented into new or existing camera systems and detects faces of persons, collects their features and compares them against templates in a database (https://findbiometrics.com). Moreover, according to Rouse (2018), facial biometric technologies belong to a category of biometric software which is able to map characteristics of a person's features mathematically. These technologies are based on advanced algorithms which compare digital images or live captures with database face-prints for the purpose of verification.

In general, biometrics refers to a sophisticated technology, which is able to identify unique physical and behavioral features of individuals (Shyam, Singh, 2016). Signs which are used within biometric authentication include the face, foot, fingerprints, palm, nail bed, geometry of hand, body smell, distribution of veins on the hand, iris, skin reflection, retina, shape of ear, DNA or teeth. On the other hand, behavioral characteristics such as the motion of the lips motion, the strength of the keystroke, one's voice, signature or walk can be utilized for the purposes of biometric authentication (Langerdenfer, Linnhoff, 2005; Barde, Zadgaonkar, 2015). In addition, according to Das (2014, p. 6), the "goal of biometrics is to positively confirm the identity of an individual and the result is to make sure that the right person gets access to the resources they are seeking to gain".

On the other hand, one of the biggest advantages of biometrics technologies could be at the same time its biggest threat. During the process of data gathering with this system, a complete image of a particular biometric data is taken. To point out, as we mentioned before, only unique patterns of this image are utilized from the biometric template, which is created and stored. The initial image, also called a raw image is deleted right after the template is created. However, here is discussion that the original images could be an interesting source of possible identify theft for high level hackers (Das, 2017).

Biometric technologies may be used in three main ways, verification, identification and screening. In this case, verification as an essential ability is used to ensure that a person or individual is in reality who he claims to be. Identification is in the majority applied in cases of discovering the identity of unknown persons. Finally, screening serves for the management and categorization of people stored in a database (Heracleous and Wirtz, 2006)

Facial biometrics and its history can be tracked back to the sketches of possible suspects within criminal investigations where portrait artists made precise reproductions of faces according to witness statements (Jones et al., 2007). In this paper authors are interested in commercial utilization and potential of these technologies among businesses operating in Slovakia.

\section{Data and Methodology}

The main aim of this article is to identify the stage of purchase behaviour of the investigated businesses operating in Slovakia, in relation to facial biometric technology. Notably, we focused our attention on 
the identification of businesses in reference to a particular stage of the AIDA model, while we further devote time to the description of the business from the selected stages. To be able to investigate this issue, we performed primary research. In order to fulfil the main aim of this, we have formulated hypothesis $\mathrm{H}_{1}$ in order to find out the level at which the consumer is according to the AIDA model or the STDC model.

$\mathrm{H}_{1}$ : We assume that more than $20 \%$ of the examined businesses will be at least in second stage of their purchase behavior according to the AIDA/STDC models.

For the purpose of our paper, we performed quantitative research where we applied questioning as a data collection method, while as a tool we used a questionnaire survey. In this research, we decided to approach businesses of relevant size and from different industries operating in Slovakia. For this purpose, we used two different forms of data collection. First of all, students from the Faculty of Economics at Matej Bel University participated as field researchers, because they were asked to visit businesses across Slovakia and to fill in the questionnaire with answers from adequate representatives of the business. Secondly, we approached businesses in Slovakia by e-mail. For this purpose, an online version of our questionnaire was created in the Google Docs application. We decided to utilize access to a database of contacts through an analytical portal because of its ability to allow us to approach as many businesses as possible. The processes of data collection was realized from September to November 2019. Within our questionnaire we utilized questions with semantic differential statements, basic optional questions or level of agreement statements, enhanced by a 7-point Likert scale to ensure a sufficient range of options.

For the purpose of our research we deliberately focused on businesses with at least 10 employees, therefore small, medium and large businesses, because the potential of this technology in microbusinesses is very small and we do not expect their interest in the implementation of facial biometric technologies. Finally, from the data collection process, we were able to reach 521 complete answers that followed representativeness criteria. The research sample was representative by two signs - the size of the business /number of employees and the region/business residence.

Within our research, we collected 521 complete answers, and the structure of these respondents can be divided into distinctive groups according to the identification criteria. We decided to distribute these respondents according to the criteria: business activity, ownership, average annual revenues, business size and region. In our research sample there were 189 manufacturing businesses (36.28\%), 62 wholesalers (11.90\%), 47 retailers $(9.02 \%)$ and 223 businesses from service industries $(42.80 \%)$. Further from the total amount, 371 businesses $(71.21 \%)$ are owned solely by Slovak owners, 19 businesses (3.65\%) are owned mostly by Slovak owners, 11 of respondents $(2.11 \%)$ are half owned by Slovak and half owned by foreigners, 32 businesses $(6.14 \%)$ are mostly owned by foreign owners and finally 88 business (16.89\%) are solely owned by foreign owners. Later, our research sample consist of 236 businesses (45.30\%) with an average annual revenues less than 2 million Euros $(€), 180$ businesses (34.55\%) with average annual revenues between 2 and 10 million Euros $(€), 75$ businesses (14.40\%) with average annual revenues between 11 and 50 million Euros $(€)$ and 30 businesses (5.76\%) with average annual revenues higher than 50 million Euros $(€)$. Figure 1 represents the distribution of businesses according to the criteria of revenues.

\begin{tabular}{|l|l|}
\hline Figure 1: Distribution of Research Sample according to Revenues \\
\hline
\end{tabular}


The research sample consists of $79.27 \%$ (413) small business with 10-49 employees, $17.49 \%$ (91) medium size businesses with 50-249 employees and finally 3.26\% (17) large businesses with more than 250 employees.

\section{Results and discussion}

The usage of facial biometric technologies in Slovakia is very young and not so wide spread, so we consider it necessary to identify in what stage of consumer behavior according to the AIDA/STDC model businesses in Slovakia are in. For this purpose, we used a combination of previous mentioned AIDA and STDC models according to Suggett (2017) and Hart (2018). Together we approached 521 businesses operating in Slovakia that participated on our research.

The results determined that $35(6.72 \%)$ of respondents are just before the AIDA model, thus they have never heard about facial biometric technologies before. On contrary, research showed that the majority of respondents, together $450(86.37 \%)$, expressed that until now they have just heard about facial biometric technologies; thus they belong to the first stage of the AIDA model. Further, only $15(2.88 \%)$ of respondents are in the second stage of the AIDA/STDC model, hence they have heard about this technology and they consider its purchase. On the other hand, only 4 respondents $(0.77 \%)$ are in the third stage, which refers to the decision making process about which facial biometric technology to purchase. Finally, even though small proportions of businesses were in the second or third stage, we were surprised that in our research sample there were 17 businesses $(3.26 \%)$ who already use facial biometric technology in their business, therefore they are in the fourth stage of this model. Figure 2 depicts the distribution of businesses by consumer behavior according the AIDA/STDC model.

\begin{tabular}{|c|c|}
\hline \multicolumn{2}{|c|}{ Figure 2: Distribution of Businesses according AIDA/STDC Model } \\
\hline $2,88 \%+3,26 \% \quad 6,72 \%$ & $\begin{array}{l}\text { - have not heard } \\
\text { about yet } \\
\text { - just have heard } \\
\text { about } \\
\text { - have herad about } \\
\text { and consider } \\
\text { purchase } \\
\text { stage of decision } \\
\text { making process } \\
\text { already use facial } \\
\text { biometric }\end{array}$ \\
\hline
\end{tabular}

\section{Source: Authors.}

The previous graph showed us that the majority of businesses are just in the first stage of AIDA/STDC model. This fact proved our assumption, that the usage of facial biometric technologies in Slovakia is not wide spread. For this reason, we can see that there is a huge space for businesses operating in this field to influence their potential customers and to create an interest for this technology, if they will communicate it properly. However, the first thing necessary to be done is the proper education of the market in the field of facial biometric technologies. Also, the majority of businesses have just heard about these technologies, they probably did not search for any further detailed information. Therefore, it is necessary to educate businesses in a market not only about what facial biometric technology is, but what functionalities and benefits it has, how businesses can utilize and implement this technology into their processes, and also what are the conditions and requirements for its implementation, including legal and ethical aspects of its usage.

To sum it up, we found out that $3,26 \%$ of businesses in Slovakia already use facial biometric technologies. Thus, together more than $96 \%$ of businesses in Slovakia represent potential consumers for facial biometric technology implementation in wide terms. However, a huge majority of them is in the situation they just have heard about them. To attract these businesses, it will be necessary to properly communicate added value and educate market about the benefits what requires longer time-period. We 
can expect that not all of them will be interested in this technology and there are also other aspects that might influence its implementation into businesses, such as legislation, attitudes or other restrictions.

Regarding the issue of the stage of consumer behavior according to the AIDA/STDC model, we have formulated hypothesis $\mathrm{H} 1$. Within hypothesis $\mathrm{H} 1$, we assumed that more than $20 \%$ of businesses will be at least in the second stage of the purchase behavior according to the AIDA/STDC model. For the purpose of hypothesis verification, we planned to utilize the SPSS program and Binominal statistical test. However, since the amount of businesses that are in the second or higher stage of the AIDA/STDC model is only $6.91 \%$ in the research sample and not at least $20 \%$ as we expected, it does not make any sense to test this prediction with statistical tests. Therefore, we can conclude that hypothesis H1 was not confirmed.

As we can see, in our assumption prevailed a very optimistic expectation about a certain level of customer behavior based on the AIDA/STDC model among businesses in Slovakia. We have to keep in mind that the topic of facial biometric technology is still very young in our country. Moreover, even though more than $86 \%$ of respondents have heard about facial biometric technology, a not very high percentage of businesses reach the consideration of its purchase, especially up to the point of the decision making process. Thus, the readiness of the majority businesses for the purchase of this technology is not in place yet. This fact could be because of to many factors such as a lack of detailed information about this technology, expected price or low perceived added value or usefulness.

Related to the classification of businesses according their reference to a particular stage of the AIDA/STDC model, we found it interesting to investigate what businesses belong to this stage. In other words, we aimed to identify which characteristics do businesses from the second and higher stage have in order to make an overview.

As we mentioned before, within the examination of the respondent's answers related to the question about stage of the AIDA model, we found out that about $86 \%$ of businesses just heard about facial biometric technology and only $6.9 \%$ of them are at least in the second stage of this model. What this means is that they have heard about facial biometric technology and already consider its purchase. The reasons why there is such a large amount of businesses that are only in the first stage may differentiate, but mainly we can talk about the low implementation of development of this technology in Slovakia.

However, on the other hand, we found it valuable to investigate the character of respondents that belong to the group which is in the second or higher stage of the AIDA model. This group contains businesses that have serious interest for this technology because they consider its purchase or are in the stage of decision making about this technology. Moreover, this group abounds also with 17 businesses that already use facial biometric technology. Thus, we find it very important to investigate what these businesses are, to what categories they belong and to determine other important information. Therefore, we make a small analysis of these businesses, in order to be able to identify their common characteristics and to create proposals. Together, this group contains 36 businesses.

Based on the industry in which these businesses operate, we can see that majority of these businesses are from the services industry (50\%), then the second highest proportion is the manufacturing industry (22.24\%), and third and fourth place are shared by the wholesale and retail industries $(13.88 \%$ each). Thus, we can conclude that under these conditions (according to the AIDA model), until now businesses from the service industry are the most oriented industry in favor of the usage of facial biometric technology. Interestingly, second place belongs to manufacturing businesses, therefore this group of businesses is also a potential customer for this technology. Wholesale and retail businesses represented similarly little less than $14 \%$ each. This fact is potentially due to the low representation of these groups in the research sample in general.

Further we took a look at the group of businesses within the second and higher stage of the AIDA model through the perspective of their ownership. In this case, we found out that the majority, $80.56 \%$, are solely owned by Slovak owners. Thus, the majority businesses that have serious interest in facial biometric technology belongs solely to the Slovak owners, therefore there is no financial or nonfinancial influence from foreign investors. This finding shows us a high orientation of Slovak businesses to facial biometric technology and its implementation. Therefore, we may see that the focus of Slovak businesses to new and high-end technologies is high and these businesses represent potential customers. 
In regard to the business size evaluation of this group, we can look through two perspectives, based on the average annual revenues or the number of employees. According to the results, we found out that small businesses (10-49 employees / revenues less than 10 million $€$ ) represent the highest proportion of businesses in this group (86\% according to the number of employees or 56\% according to the average annual revenues). Therefore, businesses commercializing facial biometric technology should focus their attention to this category of businesses.

Next, we looked the at innovativeness expressed by the answers of the businesses. As we could expect, answers that "we do not innovate at all" or "we almost do not innovate" did not appear among these businesses. 36\% of respondents expressed that they innovate constantly in their business and 30\% of respondents expressed that they innovate regularly. Thus, we can see that innovativeness of businesses in this group is very high, which reflects their interest in the adoption of new technologies.

Further, we examined what expectations prevail among businesses that have a serious interest in implementation of facial biometric technology. According to their answers, we determined the top 5 expectations (with the highest frequency). Thus, the most important expectations for these businesses is "restriction of unauthorized access of individual to selected area" together with expectation of "more effective attendance system" ( similarly chosen by 22 businesses $=61 \%$ ). Third place belongs to the "automatization of business processes" which was selected by 17 businesses (47\%). A little less important expectation for businesses (chosen by $36 \%$ ) is "simplification of business processes". Finally, "getting closer to the customer" closes the top 5 of expectations with $30 \%$ of businesses.

We can see that the expectations selected by this group of businesses almost exactly reflects expectation of whole research sample in first two (restriction of access and attendance systems). Moreover, there is a similarity also in third and fourth expectation (automatization and simplification of business processes) with overall research sample. However, in the case of the fifth expectation, there is a difference. In regard to the overall research sample, fifth place belonged to the expectation of "improved product/service", but within this group of businesses (second and higher stage of the AIDA model) fifth place is covered by the expectation of "getting closer to the customer". Here, we can see that a marketing oriented expectation is assigned by a relatively high number of respondents $(30 \%)$. Therefore, we can conclude that the orientation of businesses in this group is little bit more marketing oriented.

Similarly, we tried to reveal what benefits these businesses look for through implementation of this technology. According to the results, we found that "restriction of unauthorized access" is the top benefit that is perceived by $64 \%$ of businesses. The second highest frequency was assigned to "gain competitive advantage" by $42 \%$ of respondents. Third most attractive benefit is "elimination of mistakes" which was selected by $30 \%$ of businesses. Therefore, we can summarize that businesses in this group are mostly oriented on the benefit of securing the access of individuals, similarly as in the overall research sample. However, a large proportion of them assigned high importance to the development of a competitive advantage through implementation of facial biometric technology. Therefore, they seek more "market oriented" benefits that will help them improve their position in a market and to overtake their competitors.

In addition, we took a look at the required level of complexity of these businesses. We found out that within this group, almost $92 \%$ of businesses are interested in a single/basic form of implementation of facial biometric technology. This finding shows us that, businesses in Slovakia (even though in a higher or lower stage of the AIDA model) are not certainly prepared for an advanced/more complex form of implementation of this technology into their business. This fact could be caused by many reasons, such as a lack of information, incorrect expectation in terms of pricing, implementation difficulty or not sufficient perceived added value for their business.

\section{Conclusion}

Within our research, we did not prove our hypothesis that more than $20 \%$ of businesses are in at least second stage of the AIDA model. This fact showed us that the orientation on usage of facial biometric technologies in Slovakia is not wide spread. From this reason, we can see that there is a huge space for the commercializing of this technology by businesses, to influence their potential customers and to create an interest in this technology. Thus, the first thing we recommend to be done is the proper education of the market in the field of facial biometric technologies. Since the majority of businesses have just heard about these technologies, they probably did not search for any further detailed 
information. Therefore, it is necessary to educate businesses in a market not only about what facial biometric technology is, but also what functionalities and benefits it has, how businesses can utilize and implement this technology into their processes, and what are the conditions and requirements for its implementation, including legal and ethical aspects of its usage.

To conclude, during this analysis we determined that businesses that have a serious interest for the implementation of facial biometric technology (businesses that represent a kind of target group for the commercialization of this technology) can be characterized mainly as: small and very innovative businesses that are in hands of Slovak owners, operating mostly in the services industry. Among these businesses prevailing expectations about implementation of facial biometric technology include that they will get closer to the customer, while perceived benefits are a little bit more marketing oriented (focus on competitive advantage). Finally, these businesses are currently focused mostly on a single/basic form of technology implementation.

\section{Acknowledgments}

This paper contains partial results of the national project VEGA 1/0488/20 Market, marketing, legislative and ethical aspects of biometric technologies utilisation in the commercial sector (2020-2022, project leader Janka Taborecka-Petrovicova).

\section{References}

Barde, S., Zadgaonkar, A. S. (2015). Person Identification Using Face, Ear and Foot Modalities. The IUP Journal of Computer Sciences, 9(1), 32-46.

Das, R. (2014). Biometric Technology: Authentication, Biocryptography, and Cloud-Based Architecture. Florida:CRC Press.

Das, R. (2017). Adopting Biometric Technology: Challenges and Solutions. Boca Raton: CRC Press.

Hart, C. (2018). See, Think, Do, Care: A New Way to Communicate Your SEO Strategy. Retrieved from :

<https://www.searchenginejournal.com/seo-guide/see-think-do-care-seo-strategy/>.

Heracleous, L., Wirtz, J. (2006). Biometrics: the next frontier in service excellence, productivity and security in the service sector. Managing Service Quality, 16(1), 12-22.

Jones, P., Williams, P., Hillier, D., Comfort, D. (2007). Biometrics in retailing. International Journal of Retail \& Distribution Management, 35(3), 217-222.

Langerdenfer, J., Linnhoff, S. (2005). The Emergence of Biometrics and Its Effect on Customers. The Journal of Consumers Affairs, 39 (2), 314-338.

Shyam, R., Singh, Y. N. (2016). Multialgorithmic Frameworks for Human Face Recognition. Journal of Electrical and Computer Engineering, vol. 2016, 9

Suggett, P. (2017). Get to Know and Use, AIDA. Retrieved from: <http:// www.thebalance.com/get-to-know-and-use-aida39273>.

Rouse, M. (2018). Facial Recognition. Retrieved from: <https://searchenterpriseai.techtarget.com/definition/facialrecognition>.

4Facial Recignition. Retrieved from: <https://findbiometrics.com/solutions/facial-recognition/>. 